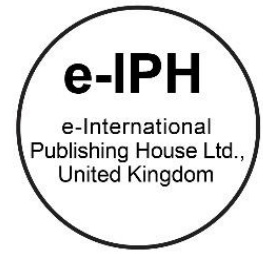

\title{
Social Environment Influence Lifestyle of Youth in Rural Area
}

\author{
Saberi Othman ${ }^{1 *}$, Nur Ikhwan Mohamad², Mohd Mohni Iskandar², Kamarul Ariff Omar³. \\ 1 Department of Biology, Faculty of Science and Mathematics, University Pendidikan Sultanm Idris, 35900, Tanjong Malim Perak, Malaysia. \\ ${ }^{2,3}$ Faculty of Sports Sciece and Coaching, Universiti Pendidikan Sultan Idris, 35900 Tanjong Malim, Perak, Malaysia. \\ ${ }^{3}$ Faculty of Architecture, Planning and Surveying, Universiti Technology MARA, Shah Alam, Selangor, Malaysia.
}

\begin{abstract}
This paper aims to discuss the influence of social environment on the lifestyle of youth in the rural area. The social environment refers to the immediate physical and social setting in which youth live or in which something happens or develops. It includes the public amenities provided by the authority to be used by the public. A healthy lifestyle was measured by asking respondents to respond to questions whether social environment facilities provided in the area influence the youth lifestyle. Social environment positively influences the healthy lifestyle of youth. However it differed between areas.
\end{abstract}

Keywords: Social Environment, Lifestyle, Youth

ISSN: 2398-4287@ 2017. The Authors. Published for AMER ABRA by e-International Publishing House, Ltd., UK. This is an open access article under the CC BYNC-ND license (http://creativecommons.org/licenses/by-nc-nd/4.0). Peer-review under responsibility of AMER (Association of Malaysian Environment-Behaviour Researchers), ABRA (Association of Behavioural Researchers on Asians) and cE-Bs (Centre for Environment-Behaviour Studies), Faculty of Architecture, Planning \& Surveying, Universiti Teknologi MARA, Malaysia.

\subsection{Introduction}

Many works on influence of social environment on adolescents and youth focussed in urban area (e.g Van Der Hosrst et al., 2007; Van Hecke et al., 2016; Lederbongan et al, 2011; Parks et al., 2003; Addy et al., 2004; Lehmann et al., 2008). Similarly, works on social environment and well-being in Malaysia also concentrate in the urban environment (e.g. Streetheran and Konijnendijk van den Bosch, 2014; Meredith, 1982; Badaruddin Mohamed, 2002; Fatemah Hosseini, 2016; Othman et al., 2016). Despite increasing evidence social environments influence on youth in the urban area, little attention has been addressed the relationship for rural youth. Youth, either urban or rural-dweller, is the most important stage of one's life because at this age their physical as well as their mental strength is at the top level, so it is the most appropriate stage to build the basis or foundation of life ahead. It is the time figure out everything about the world and develops their personality. Those experiences and character qualities contribute the youth to be productive members or liabilities to the community and society (e.g. Fraser-Thomas et al., 2007; Nansel et al., 2001; Slee, 1995 ). Several factors have been reported the characters qualities of adults, such as physical environment and social setting which is termed as social environment (e.g. Park et al., 2004; Saelens and Handy, 2008; Badland and Schofield, 2005). Thus, social environment plays a significant role in developing youth personality and well-being perception.

The social environment, or, or sociocultural context refers to the immediate physical environment and social setting in which people live or in which something happens or develops. The physical environment in this paper is referred to a micro level environment which includes the public library, multipurpose hall, places of worship such as mosque and church, facilities for exercise and recreation, hospital and clinics, schools and other academic institution, public transport and other. The social setting includes the community and culture that the individual was educated or lives in and the people and institutions with whom they interact (Barnett and Casper, 2001). Social setting is influenced by social variables, the social networks and social supports. Social networks are referred to the web of person-centred social ties (Berkman and Glass, 2000). In this paper, social networks will be assessed through the frequency of contacts with family members, friends and well-being assessment with society. Social supports refers to the assistance

\footnotetext{
${ }^{*}$ Corresponding author. Tel.:

E-mail address: saberi@fsmt.upsi.edu.my
}

ISSN: 2398-4287@ 2017. The Authors. Published for AMER ABRA by e-International Publishing House, Ltd., UK. This is an open access article under the CC BYNC-ND license (http://creativecommons.org/licenses/by-nc-nd/4.0/). Peer-review under responsibility of AMER (Association of Malaysian Environment-Behaviour Researchers), ABRA (Association of Behavioural Researchers on Asians) and cE-Bs (Centre for Environment-Behaviour Studies), Faculty of Architecture, Planning \& Surveying, Universiti Teknologi MARA, Malaysia. 
that youth received from social networks, whether in term of instrumental supports, emotional or information. The interaction could be happened through personal contact, or through media such as telephone, the internet, and letter.

The nature and setting of physical environment may influence youth activity, relationship with community, motivation, and wellbeing perception. For example, even though the area is providing public amenities such as library, sport and recreation facilities, few number of youth used it, if the facilities not in good condition, far from their home, and always unavailable whenever needed. The density of youth also influences the frequency using the facilities. Continuous experienced of the uncertain may make youth become stressful. Stressful circumstances make people feel worried, anxious, and unable to cope and impatience. The nature and setting of physical environment have been reported can influence the lifestyle and wellbeing of young children within that environment (Edward and Bromfield, 2009).

Lifestyle is denoted as the interests, opinions, behaviours, and behavioural orientations of an individual, group, or culture (Kahle and Close, 2011). The term is referred to a combination of determining intangible or tangible factors. Tangible factors relate specifically to demographic variables, i.e. an individual's demographic profile, whereas intangible factors concern the psychological aspects of an individual such as personal values, preferences, and outlooks (Adorno, 1991). Thus, the aim of this study is to investigate the influence of social environment on the lifestyle of youth in selected rural area. The life style in this paper is assessed by intangible factors of personal values on social environment facilities.

\subsection{Methodology}

\subsection{Selection of Study Area}

Two areas have been selected to conduct the study, namely Jengka area in Maran District, Pahang and Kota Samarahan in Sarawak. Selection of these study areas was based on their location in the rural area, interview and discussion with the focus group (FGD) of youth. Data from FGD showed that Jengka and Kota Samarahan have physical environment facilities provided by the authority and active participation of youth during FGD.

\subsection{Respondents}

Respondents were determined by referring to Maran Parliamentary voting area which includes Federal Land Development Authority 2013 (, 2010) and National Population Census 2010 (Malaysian Statistics, 2010). There were 200 houses were identified with youth aged 15 - 24 and recorded for Jengka in Maran, Pahang and similar 200 houses identified for Kota Samarahan Sarawak. Respondents were given questionnaire consisting of three sections. Section A questionnaire for demographic (Section A), and Section $B$ questionnaire for social environment and section $C$ well-being questionnaire. There was 64 male, and 66 female youth responded and answered all the questions for Jengka area, in Pahang; For Kota Samarahan, in Sarawak, there were 84 male and 46 female responded.

\subsection{Questionnaire}

Questionnaire for demographic (Section A) include a type of accommodation, a location of accommodation, age, ethnic group, religion, and level of education, number of persons occupying the accommodation, jobs, and monthly income. Section $B$ is the questionnaire for physical environments such as public library, multipurpose hall, places of worship such as mosque and church, facilities for exercise and recreation, hospital and clinics, schools and other academic institution and public transport. Items were rated from 1 to 5 scale. Based on the literature review, indicators for well-being questionnaire (Section B) identified as the standard of living, health, physical activity, emotion, security, youth participation in the community, future hope and moral values (e.g. Cummins et al., 2012; Tomyn and Cummins, 2011. Items were rated from 1 to 5 scale; a similar scale has been used by authors such as Tennant et al. (2007), Deci et al. (2001), Gagne (2003) and Ryan and Frederick (1997). Scale data then converted to percentage. Rating $80 \%$ and above considered high, 51 to 79 intermediate, while 50 and below considered weak. All questionnaires then were analysed by SPSS. The alpha coefficient for the physical environment showed between minimum values of 0.74 and maximum value of 0.96 , whilst alpha coefficient for eight items of wellbeing questionnaire is .874 , suggesting that the items have relatively high internal consistency, because a reliability coefficient of .70 or higher is considered acceptable in most social science research situations (e.g. Cortina, 1993; Tavakol and Dennick, 2011).

\subsection{Results}

\subsection{Data Cleaning and Preparation}

All cases were examined for response questionnaires set. Participants that consistently scored minimum (1) or maximum (5) for all physical environment and all eight domains for well beings considered unreliable and removed from the analysis. In the end, the number of reliable answered questionnaire set was 260 for the whole study area; 130 for Jengka (64 male and 66 female) and 130 for Kota Samarahan (84 male and 46 female). 


\subsection{Demography}

Table 1 shows the number of male and female of the respondents and age group analysis. Among 260 participants involved in the study, $148(56.9)$ were male, and $112(43.1 \%)$ were female. Age group of 18-20 years old constitute the highest number, followed by age group $21-23(22.7 \%), 15-17$ years age group is $20.4 \%$, and the lowest is age group $24-25(10 \%)$.

Table 1. Gender analysis and age group of respondents

\begin{tabular}{llll}
\hline & & $n$ & $\%$ \\
\hline Gender & Male & 148 & $56.9 \%$ \\
& Female & 112 & $43.1 \%$ \\
\hline Age Group & $15-17$ & 53 & $20.4 \%$ \\
& $18-20$ & 122 & $46.9 \%$ \\
& $21-23$ & 59 & $22.7 \%$ \\
& $24-25$ & 26 & $10.0 \%$ \\
\hline
\end{tabular}

High percentage of the participants having low education level, and only $10 \%$ of them have the opportunity to go higher level of education (7.7\% Diploma, and $2.7 \%$ university graduate) (Table 2).

Table 2. Analysis of the education level of the respondents

\begin{tabular}{ccc}
\hline Education level & $\mathrm{n}$ & Percentage (\%) \\
\hline Primary school & 17 & 6.5 \\
Lower secondary (form 3) & 39 & 15 \\
Upper secondary (form 5) & 156 & 60 \\
Upper secondary (form 6) & 14 & 5.4 \\
Certificate & 7 & 2.7 \\
Diploma & 20 & 7.7 \\
Degree & 7 & 2.7 \\
\hline
\end{tabular}

Table 3. Monthly income of respondents and family income

\begin{tabular}{|c|c|c|c|c|}
\hline \multirow{2}{*}{$\begin{array}{l}\text { Income group } \\
\text { (RM) }\end{array}$} & \multicolumn{2}{|c|}{ Respondents } & \multicolumn{2}{|c|}{ Family } \\
\hline & $\mathrm{n}$ & $\%$ & $\mathrm{n}$ & $\%$ \\
\hline No income & 120 & 46.3 & 0 & 0 \\
\hline$<500$ & 41 & 15.9 & 3 & 1.2 \\
\hline $501-1000$ & 34 & 13.2 & 16 & 6.2 \\
\hline $1001-1500$ & 12 & 12.2 & 28 & 10.8 \\
\hline $1501-2000$ & 14 & 5.4 & 48 & 18.5 \\
\hline $2001-2500$ & 7 & 2.7 & 43 & 16.5 \\
\hline $2501-3000$ & 10 & 3.8 & 55 & 21.2 \\
\hline $3001-3500$ & 0 & 0 & 32 & 12.3 \\
\hline $3501-4000$ & 0 & 0 & 21 & 8.1 \\
\hline$>4000$ & 1 & 0.4 & 14 & 5.4 \\
\hline
\end{tabular}

More than $70 \%$ of respondents having monthly income less than RM 1,500 which considered as rural poor, $10 \%$ of them earned less than RM 3,000 a month, and less than $1 \%$ earned >RM 4,000 (Table 3). About 35\% of family earned less than RM 2,000 a month categorised as rural poor. About $50 \%$ of the family earned RM 2,000 -3,500 per month, and about $13 \%$ of the family earned between RM 3,500-4,000 per month.

Table 4. Number of family and family members live in the house

\begin{tabular}{lll|lll}
\multicolumn{5}{c}{} & \multicolumn{5}{c}{ Pamily members } & $\mathrm{n}$ & Percentage $(\%)$ & No of family & $\mathrm{n}$ & Percentage $(\%)$ \\
\hline $1-3$ & 21 & 8.1 & 1 & 204 & 78.5 \\
$4-6$ & 142 & 54.6 & 2 & 45 & 17.3 \\
$7-9$ & 87 & 33.5 & 3 & 6 & 2.3 \\
$10-14$ & 10 & 3.8 & 4 & 5 & 1.9 \\
\hline
\end{tabular}

It is common for low income group living together in a crowded house. Table 4 shows that some houses occupied by 7-9 occupants $(87 \%)$. About $3.8 \%$ of the houses occupied by $10-14$ family members. Many houses occupied by one family $(78.5 \%)$, however some houses shared by 2 families (17.3\%), 3 families $(2.3 \%)$ and even as many as 4 families $(1.9 \%)$.

Majority of youth are staying with family (91.5\%) (Table 5), probably representing students ages below 20 years old (Table 1). Only small percentage staying alone or renting house. These group of youth probably those who already engaged in working. To own motor vehicles need substantial amount of money especially for petroleum and regular maintenance. However, about $50 \%$ of the respondents answered they have motor vehicles motorcycles (33.1\%) and cars (18.1\%) (Table 6). Most families own motor vehicles, $78.4 \%$ cars and $15.8 \%$ motorcycles. Only $2.7 \%$ of families do not own motor vehicles. 
Table 5. With whom the respondents live

\begin{tabular}{lll|lll}
\hline Staying in & $\mathrm{n}$ & Percentage (\%) & Ownership & $\mathrm{n}$ & Percentage (\%) \\
\hline Alone & 7 & 2.7 & Own house & 6 & 2.3 \\
Family & 238 & 91.5 & Family house & 226 & 86.9 \\
Relatives & 1 & 0.4 & Rented & 28 & 10.8 \\
Friends & 14 & 5.4 & & & \\
\hline
\end{tabular}

Table 6. Type of vehicles owned by the participants and family

\begin{tabular}{c|cc|c|c}
\hline \multirow{2}{*}{ Type of vehicles } & \multicolumn{2}{|c|}{ Respondents } & \multicolumn{2}{c}{ Family } \\
\cline { 2 - 5 } & $\mathrm{n}$ & Percentage (\%) & 8 & Percentage $(\%)$ \\
\hline Bicycles & 17 & 6.5 & 41 & 3.1 \\
Motorcycles & 86 & 33.1 & 204 & 15.8 \\
Cars & 47 & 18.1 & 7 & 78.4 \\
None & 110 & 42.3 & 2.7 \\
\hline
\end{tabular}

About $37 \%$ of the respondents are employed. $11.2 \%$ unemployed but do active in finding job, as compared to $6.9 \%$ unemployed but actively finding for job. About $44 \%$ are unemployed but there still schooling either in secondary school or in higher institutions (Table 7).

Table 7. Employment status of the Respondents

\begin{tabular}{lcc}
\hline Employment Status & $\mathrm{n}$ & Percentage (\%) \\
\hline Employed & 98 & 37.7 \\
Unemployed (non-active) & 29 & 11.2 \\
Unemployed (active) & 18 & 6.9 \\
Unemployed (students) & 115 & 44.2 \\
\hline
\end{tabular}

\subsection{Physical Environment}

Analysis of level of satisfaction of youth towards physical environment facilities is represented in Table 8. Youth perceived the physical environment in the rural is in the level of intermediate. Exception for primary school they considered as high rating $(80 \%)$. Education is an important factor in country development, thus government providing good facilities for the country, urban and rural areas. However, rating for sidewalks or facility for pedestrian is below $50 \%(40.6 \%)$. Probably, the authority do feel sidewalks is necessary in the rural area.

Table 8. Analysis of respondent's satisfaction on physical environment

\begin{tabular}{|c|c|c|c|}
\hline \multicolumn{2}{|c|}{ Category of Physical Environment } & Mean Level of Satisfaction (\%) & S.D \\
\hline \multirow{5}{*}{ Community facilities } & Public library & 65 & 18.52 \\
\hline & Multipurpose hall & 67 & 19.33 \\
\hline & Futsal field & 71.1 & 21.09 \\
\hline & Badminton court & 70.9 & 20.45 \\
\hline & Basketball court & 65.4 & 19.34 \\
\hline \multirow[t]{4}{*}{ Sport and recreation } & Football field & 63.9 & 18.55 \\
\hline & Recreation park & 71.2 & 20.73 \\
\hline & Gymnasium & 70.6 & 20.13 \\
\hline & Jogging track & 41.2 & 15.31 \\
\hline \multirow{2}{*}{ Health facilities } & Government clinics & 75.5 & 21.76 \\
\hline & Private clinics & 72.2 & 20.25 \\
\hline \multirow[t]{2}{*}{ Education } & Primary school & 80.5 & 23.21 \\
\hline & Secondary school & 77.5 & 20.57 \\
\hline \multirow[t]{3}{*}{ Economic activity } & Grocery store & 76.6 & 21.11 \\
\hline & 24 hours shop & 74.6 & 20.34 \\
\hline & Restaurants & 75.0 & 22.74 \\
\hline \multirow{3}{*}{ Public transportation } & Bus & 68.2 & 19.32 \\
\hline & Taxi & 66.6 & 18.41 \\
\hline & Road systems & 74.1 & 21.33 \\
\hline \multirow{3}{*}{ Infrastructure and utility } & Sidewalks or pedestrian & 40.6 & 13.30 \\
\hline & Parking spaces & 73.2 & 20.48 \\
\hline & Public phone & 65.4 & 18.91 \\
\hline
\end{tabular}

Youth intermediate perception on the physical environment facilities in the rural areas translated on the well-being eight domains rating (Table 9). Table 9 shows well-being rating for the whole samples and between gender of youth in rural area (Jengka and Kota Samarahan). Majority of the samples is in the intermediate rating, and none in the high rating suggesting that youth in this community perceived moderate well-being category. They satisfy with their health shown by the highest percentage. The lowest score of wellbeing rating is youth future hope, suggesting that they do not have the confident on their future, probably due to less exposure to higher education, culture or community factor. 
The well-being rating between male and female youth do not differ much, but percentage of some domains for male slightly higher compared to female. Analysis between genders showed that male have the positive perception on health, physical activity, emotion and safety. While, female is more positive in participation in the community activity and moral values. The rest of the well-being rating do not show differences between male and female.

Table 9. Well-being rating of youth in rural area

\begin{tabular}{|c|c|c|c|c|c|c|c|}
\hline \multirow[t]{2}{*}{ Well-being domains } & \multicolumn{2}{|c|}{ All Samples $(n=276)$} & \multicolumn{2}{|c|}{ Male $(n=148)$} & \multicolumn{2}{|c|}{ Female $(n=112)$} & \multirow[b]{2}{*}{$\mathrm{M} 2-\mathrm{M} 3$} \\
\hline & M1 & SD & M2 & SD & M3 & SD & \\
\hline Standard of living & 62.31 & 22.06 & 63.28 & 22.28 & 61.36 & 22.00 & 1.92 \\
\hline Health & 77.31 & 21.44 & 79.30 & 20.19 & 75.38 & 22.57 & 3.92 \\
\hline Physical activity & 70.19 & 23.10 & 71.88 & 22.49 & 68.56 & 23.74 & 3.32 \\
\hline Emotion & 74.81 & 20.29 & 75.78 & 19.90 & 73.86 & 20.77 & 1.92 \\
\hline Safety & 73.85 & 21.53 & 75.00 & 22.27 & 72.73 & 20.90 & 2.27 \\
\hline $\begin{array}{l}\text { Youth participation in community } \\
\text { activity }\end{array}$ & 60.96 & 22.66 & 60.16 & 22.59 & 61.74 & 22.87 & -1.58 \\
\hline Future hope & 56.92 & 23.29 & 59.38 & 23.35 & 54.55 & 23.16 & 4.83 \\
\hline Moral values & 64.23 & 22.08 & 61.33 & 28.49 & 67.05 & 21.10 & -5.72 \\
\hline Mean & 67.57 & 14.77 & 68.26 & 15.86 & 66.90 & 13.74 & \\
\hline
\end{tabular}

\subsection{Discussion}

The area chosen in this study is a typical rural area provided with physical environment facilities. The population is mixed between races in Malaysia, namely Malay, Chinese, Indian, Iban, Bidayuh, Melanau, however not in the similar ratio. The male is slightly higher compared to female respondents, probably the reflection from male and female ratio of 106:100 (Department of Statistics, Malaysia, 2014). The profile of respondents shows majority of them are secondary school leaver, age 17-20 years old and low income (RM 2,000 and less). Only small percentage (about 10\%) have been exposed to higher education. Many of them still dependent on their parents $(\geq 90 \%)$, reflected in their income and the high number of occupants in the family house. Without good academic qualification, it hard times for youth to engage in good jobs which promise higher income. Only $37.7 \%$ of the youth are employed, $18.1 \%$ unemployed, and $44.2 \%$ unemployed but still continue their education. Some of the unemployed are not active in finding a job, most probably they feel comfortable with their parents, or due to low academic qualification, thus difficult to enter the job market. Some youth own motor vehicles $( \pm 50 \%)$, mostly motorcycles $(33.1 \%)$, and about $18 \%$ own cars. Motorcycles and bicycles are common means of transportation in the rural areas.

Youth in the study area shows very actively involved in the activities related to sports and recreation, reflected in the high perception score of the physical environment. They were satisfied with physical environment provided by the authority. Discussion with focus group of youth rectified that they satisfied in term of the condition of the facilities, number, and distance from their house. Previous works also suggested that the distance to sports facilities affect usage of the facilities (e.g. Seng Ah Lee et al., 2016; Limstrand and Rehrer, 2008; Ranchod et al., 2014). Some sports facilities, such as gymnasium, needs high-cost maintenance, do not provide in rural area. Thus it shows the lowest perception (41.2\%). Based on the focus group discussion revealed that a number of respondents do not quiet satisfy the way the facilities being maintained. For example, futsal field was locked when its needed and the person who keep the key was not around. Public facilities need responsible users in order to ensure the facilities always available in good conditions to be used. For, rural areas the condition of physical environment in the study area considered in good condition and well maintained. This reflect positive lifestyle of youth in the study area.

Well-being rating do not reflect their demography. Most of the well-being rating are intermediate, shows that they are satisfy with their moderate lives. They feel comfortable and satisfy with the facilities for health, physical activity, their emotions and safety environment. A similar finding has been reported for youth in urban marginalised community (e.g., Othman et al., 2016). However, they feel worried about other factors shows by lower well-being rating on the standard of living, moral values, and participation in community activity and future hope. In fact, future hope score the lowest well-being rating (56.92\%). If compared between genders, female rating shows lowest at 54.55 compared to male at 59.38 . Staying in the rural area, without appropriate academic qualification in deed influenced youth hope for their future. Future hope of rural youth is at the lower level of intermediate well-being index. Wellbeing rating for future hope make female youth worry which discussed during FGD with a group of youth. Security around the community area has been said not too secure for female, especially at night. The insecurity for female is reflected in their well-being rating.

Well-being index in this study is not directly comparable to Malaysian Youth National Index because of differences in domain's category. However, several domains can be compared based on the criteria indicator. The Well-being index of this study shows variation with national index. The standard of living (62.3\%), Physical activity $(70.19 \%)$ is higher in this study compared to national youth well-being index $46.9 \%$ and $30.2 \%$ respectively (Wasatch $\mathrm{Hj}$ Mohamad, 2015). However, health (77.31\%) is lower compared to a national value of $97.4 \%$. Youth in the rural area happy with their economic well-being because less spending compared to an urban 
community. Whilst in urban area every activity require money, as reported by Cheryl Teh (2014) that well-being of Malaysian youth is positively related to income.

For future development of youth in certain rural areas, several measures need to be considered. Such consideration include looking into educational curricula that meet the needs of youth, both urban and rural. Another issue needing attention is parents' lack of support to their children's education. This is especially the case in ethnic minority communities and especially for girls where traditional practices of keeping children out of school and girls marrying at a very early age are common.

\subsection{Conclusion}

In conclusion, social environment highly influenced the lifestyle of youth in the rural area. In this study area, youth perceived the availability of social environment in term of physical facilities as positive perception. The positive perception on physical environment facilities is reflected on the intermediate rating of well-being, except they have some reservation on future hope.

\section{Acknowledgements}

We would like to express my word of thanks to Ministry of Higher Learning, for allowing me to use research grant, Long Term Research Grant Scheme (LRGS), University Malaysia Kelantan (UMK) as our Research Programme leader, and Universiti Pendidikan Sultan Idris for allowing me to attend this conference.

\section{References}

Adorno, T. W. (1991). The culture industry: Selected essays on mass culture. Routledge Publishers, London.

Barnett, E. and Casper, M. (2001). A Definition of "Social Environment", American Journal of Public Health, March 2001, Vol. 91, No. 3.

Badland, H. M, Schofield, G. M. (2005). The built environment and transport-related physical activity: what we do and do not know. Journal of Physical Activity and Health. 2, 435-444.

Berkman L, Glass T. (2000). Social integration, social networks, social support, and health. In: Berkman L, Kawachi I, editors. Social Epidemiology. New York: Oxford University Press, pp. 137-173.

Cheryl Teh Li Fern (2014). Wellbeing and Its Determinants - Case of Malaysia. Taylor's College, Kuala Lumpur Malaysia.

Cummins, R.A., Woerner, J., Weinberg, M.,Collard, J., Hartley-Clark, L.,Perera, C., and Horfiniak, K. (2012). The Wellbeing of Australians - Quantity and Quality of Sleep. Australian Unity Wellbeing Index Report 27.0. Australian Centre on Quality of Life Deakin University, 221 Burwood Highway Melbourne, Victoria 3125, Australia

Cortina, J.M. (1993). What is coefficient alpha? An examination of theory and applications. Journal of Applied Psychology, Vol 78(1), 98-104.

Deci, E. L., Ryan, R. M., Gagné, M., Leone, D. R., Usunov, J and Kornazheva, B. J. (2001). Need Satisfaction, Motivation, and Well-Being in the Work Organizations of a Former Eastern Bloc Country: A Cross-Cultural Study of Self-Determination. Pers Soc Psychol Bull August 2001 vol. 27 no. $8930-942$.

Edwards, B. and Bromfield, L. (2009). Neighbourhood influences on young children's conduct problems and pro social behaviour: evidence from an Australian national sample. Children and Youth Services Rev. 31(3), 317-24.

Fraser-Thomas , J. L., Côté, J. and Deakin, J. (2007). Youth sport programs: an avenue to foster positive youth development. Journal Physical Education and Sport Pedagogy, 23 Jan 2007, 19-40.

Gagne, M. (2003). Autonomy Support and Need Satisfaction in the Motivation and Well-Being of Gymnasts. Journal of Applied Sport Psychology,Volume 15, Issue 4, $372-390$.

Kahle, L. R. and Close, A. G. (2011). Consumer Behavior Knowledge for Effective Sports and Event Marketing. New York: Routledge.

Limstrand, T. and Rehrer, N. J., (2008). Young people's use of sports facilities; A Norwegian study on physical activity. Scand. J. Public Health 36(5) $452-459$.

Mohamed, Badaruddin. (2002). Planning for the Children of the Future The Case of Malaysia. Paper presented at the Children and the City Jordan, Amman.

Nansel, T. R., Overpeck, M., Pilla, R. S., Ruan,W. J., Simons-Morton, B., and Scheidt, P. (2001). Psychosocial Adjustment. JAMA. 285(16), $2094-2100$.

Park, N., Peterson, C. and Seligman, M. E. P. (2004). Strengths of Character and Well-Being. Journal of Social and Clinical Psychology Vol. 25 (5), $603-619$.

Ranchod, Y. K., Diez Roux, A. V., Evenson, K. R., Sánchez, B. N., \& Moore, K. (2014). Longitudinal associations between neighborhood recreational facilities and change in recreational physical activity in the multi-ethnic study of atherosclerosis, 2000-2007. American Journal of Epidemiology, 179, 335-343

Ryan, R. M. and Frederick, C. (1997). On Energy, Personality, and Health: Subjective Vitality as a Dynamic Reflection of Well-Being. Journal of Personality Volume 65 , Issue 3, pages 529-565.

Slee, P. T. (1995). Bullying in the playground: the impact of inter-personal violence on Australian children's perceptions of their play environment. Child Environ. (12), $320-327$. 
Saelens, B. E. and Handy, S. L. (2008). Built Environment Correlates of Walking: A Review. Med. Sci. Sports Exerc. 40 (7), 550-566.

Sang Ah Lee, Yeong Jun Ju, Joo Eun Lee, In Sun Hyun, Jin Young Nam, Kyu-Tae Han and Eun-Cheol Park (2016). The relationship between sports facility accessibility and physical activity among Korean adults. BMC Public Health 16: 893-899.

Tavakol, M. and Dennick, R. (2011). Making sense of Cronbach's alpha. Int J Med Educ. 2: 53-55.

Tennant, R., Hiller, L., Fishwick, R., Platt, S., Joseph, S., Weich, S. Parkinson, J., Secker, J. and Stewart-Brown, S. (2007). The Warwick-Edinburgh Mental Well-being Scale (WEMWBS): development and UK validation. Health and Quality of Life Outcomes 20075:63

Tomyn, A. J. and Cummins, R. A. (2011). The Subjective Wellbeing of High-School Students: Validating the Personal Wellbeing Index-School Children. Journal of Hapiness Studies 12(5), 897-914. 